\section{Consistent health inequalities in Europe: the importance of labour market disadvantage}

\author{
Nico Dragano, Morten Wahrendorf
}

In this issue, Vandenheede et $a l^{1}$ publish new evidence for the presence of socioeconomic inequalities in all-cause mortality in three countries from Central/Eastern Europe (CEE) and in Russia. Although each of the four countries has faced different transitions in their population health after the fall of the Iron Curtain, relative differences in mortality are found in each of the four countries. Further, results are comparable to existent findings of differences in mortality from other, more consolidated European countries. ${ }^{2} 3$ In other words, today's European countries (as well as many countries beyond Europe) face relative health differences that are found irrespectively of their broader social, political and historical context. This underlines the need for conceptual and empirical research to identify common mechanisms explaining the universality of health inequalities.

One such common mechanism is supposed to be the organisation of labour markets. Their basic principles are comparable in all western-type economies where individuals sell their labour force and specific qualifications on the labour market. Those principles are of interest because employment is crucial for health in many positive and negative ways. First, employment is the main source of income for the large majority, and thus determines the material circumstances that are then related to numerous health-related risks and resources. Second, it is well known that unemployment and precarious employment are particular strong predictors of impaired health and premature mortality. ${ }^{4}$ Third, work influences mental and physical health via a large range of physical and psychosocial occupational risk factors. We may thus assume that labour markets play a fundamental and universal role in generating the reported

Institute for Medical Sociology, Centre for Health and Society, Medical Faculty, University of Düsseldorf, Düsseldorf, Germany

Correspondence to Professor Nico Dragano, Institute for Medical Sociology, Centre for Health and Society, Medical Faculty, University of Düsseldorf,

Universitaetsstrasse 1, Düsseldorf 40255, Germany; dragano@med.uni-duesseldorf.de inequalities in mortality in market-based economies.

Using primary data from a large database, Vandenheede et al find that education (usually related to SEP in early midlife ${ }^{5}$ ) together with two measures of current material circumstances (perceived food deprivation and poor household amenities) had independent effects on mortality risks. These effects are plausible as each factor is obviously linked to health (eg, via health-related behaviours or exposure to physical hazards). Although employment is not directly addressed, it is likely that it is an important factor in that respect as it is highly interrelated with education and material circumstances. In this perspective, work and employment conditions are a fundamental link between education, material deprivation and health.

We thereby not only mean a low occupational position during working life or at a single point of the employment history (either in terms of occupational class or occupational status) but, following a lifecourse perspective, specific types of employment histories (eg, precarious and unstable careers, etc.) that are related to labour market disadvantage and poor working conditions. ${ }^{6}$
From a research perspective, this means an extension of the analytical time frame to consider employment sequences (eg, employment histories instead of single jobs only). Furthermore, it seems promising to analyse in depth how education and further qualification is related to labour market disadvantage during working life and whether associations are consistent across countries. Along these lines, we believe that the core driving force of health inequalities in adults is the way how individuals are related to the labour market and what types of employment histories they have. These types do differ substantially not only in terms of accumulated labour market disadvantage but also in terms of recurrent exposure to physical, psychosocial and financial adversity.

Data from the Survey of Health, Ageing and Retirement in Europe (SHARE) may illustrate this approach. In addition to individuals' highest educational degree (based on ISCED, which we categorised as Vandenheede et al), the survey contains detailed descriptions of previous employment histories for each participant. These data were collected retrospectively at wave 3 of SHARE (2008/09) in 13 countries (also called SHARELIFE ${ }^{7}$ ). From these descriptions, we created an index of labour market disadvantage during working life for those who already left the labour market at wave 3 (and had an employment career of at least 5 years). The index is based on the following information: whether an involuntary job loss has occurred (either because of being laid off or due to plant closure), the occupational position in respondents' main job

Educational differences in labour market disadvantage

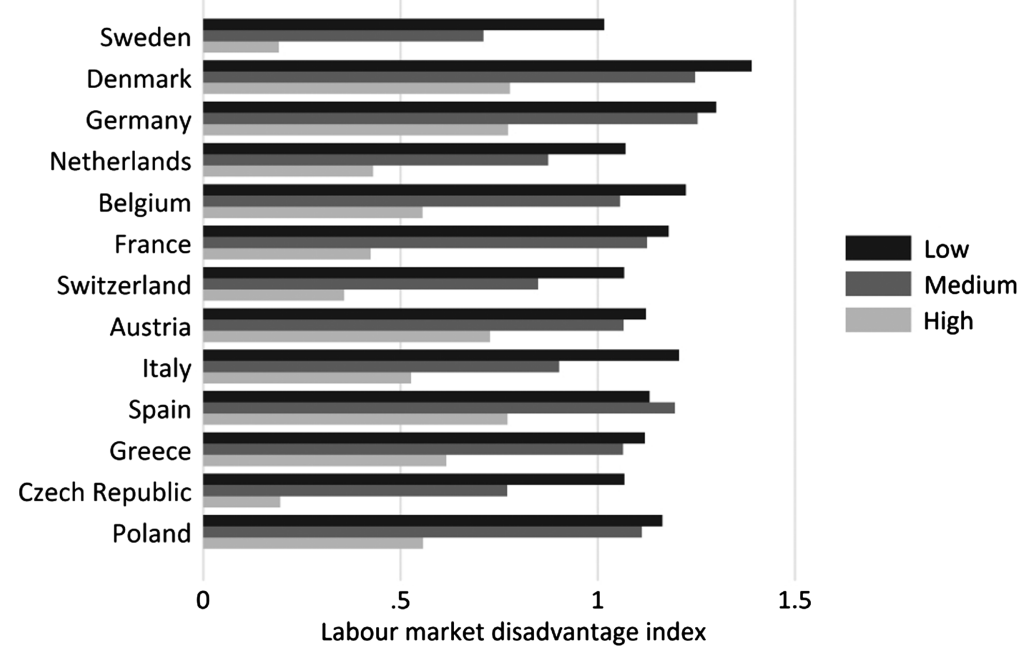

Figure 1 Educational differences in labour market disadvantage ( $\mathrm{N}=11$ 193; SHARE study; bar colour=level of education). 
(based on the skill level within the ISCO classification) and lastly whether an episode of unemployment has happened. For each of these factors, a binary indicator was created, resulting in an additive sum score ranging from 0 (less disadvantage) to 4 (most disadvantage).

Figure 1 displays the mean score by education for each of the 13 countries. We see that men and women with high education report lowest levels of labour market disadvantage in their previous employment history. Importantly, this association is consistent across all 13 countries. This means that the risk of experiencing labour market disadvantage during working life is clearly related to education in all countries under study. This finding is in line with what we know about the functioning of labour markets, in general, and personal careers, in particular, but the consistency and the strength is noteworthy as it indicates common chains of risks with a high relevance for health inequalities research.

It is also interesting that the countries from Central Europe (Czech Republic and Poland) with their particular historical transition do not differ much from other European economies, including the more egalitarian Scandinavian countries with extended welfare policies. We thus believe that existing labour market economies are a common trait of western societies, which, to a certain extent, does generate social and health inequalities in a comparable manner. Yet, it is important to note that existing regulations and labour market policies may nevertheless play an important role in reducing health differences, for example, through policies offering social provision to those who experience labour market disadvantage ('decommodification') or, maybe even more importantly, through specific regulations of active labour market policies (ALMP). ${ }^{8-10}$ In fact, recent empirical findings suggest associations between the amount of ALMP (including measures like further education among the workforce), individual working conditions and workrelated health. ${ }^{1112}$

To summarise, we think that it is an important task for research and practice to achieve a better understanding of the interrelated issues of primary education, lifelong qualification, labour market disadvantage, individual career opportunities, working conditions and health. This requires a shift from the simple analyses of long-term effects to a life-course perspective, where individual life courses (ie, employment histories) are considered in its entirety. Further, by adopting this approach we need to consider the complexity of life courses and that health determinants are not competent, but rather interrelated-each adding a piece to the puzzle. Finally, at the macro level, an extension of approaches is necessary that goes beyond classic welfare state typologies and includes other domains related to the dynamics of labour markets.

Correction notice Reference 11 and figure 1 have been revised since published Online First.

Acknowledgements This paper uses data from SHARE wave 4 release 1.1.1, as of March 28 2013, or SHARE wave 1 and 2 release 2.6.0, as of 29 November 2013, or SHARELIFE release 1, as of 24 November 2010. The SHARE data collection has been primarily funded by the European Commission through the 5th Framework Programme (project QLK6-CT-2001-00360 in the thematic programme Quality of Life), through the 6th Framework Programme (projects SHARE-I3, RII-CT-2006-062193, COMPARE, CIT5-CT-2005-028857, and SHARELIFE, CIT4-CT-2006-028812) and through the 7th Framework Programme (SHARE-PREP, No 211909, SHARE-LEAP, No 227822 and SHARE M4, No 261982). Additional funding from the U.S. National Institute on Aging (U01 AG09740-13S2, P01 AG005842, P01 AG08291, P30 AG12815, R21 AG025169,

Y1-AG-4553-01, IAG BSR06-11 and OGHA 04-064) and the German Ministry of Education and Research as well as from various national sources is gratefully acknowledged (see http://www.share-project.org for a full list of funding institutions).

Contributors ND and MW drafted and wrote the editorial. Data analyses were performed by MW.

Competing interests None.

Patient consent Obtained.

Ethics approval Obtained from the institutional review board at University of Mannheim, Germany.

Provenance and peer review Commissioned; internally peer reviewed.

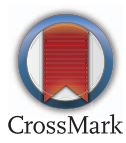

To cite Dragano N, Wahrendorf M. J Epidemiol Community Health 2014;68:293-294.

Published Online First 13 January 2014

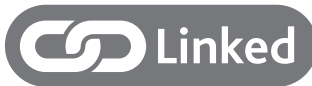

http://dx.doi.org/10.1136/jech-2013-203057

J Epidemiol Community Health 2014;68:293-294. doi:10.1136/jech-2013-203655

\section{REFERENCES}

1 Vandenheede $\mathrm{H}$, Vikhireva $\mathrm{O}$, Pikhart $\mathrm{H}$, et al. Socioeconomic inequalities in all-cause mortality in the Czech Republic, Russia, Poland and Lithuania in the 2000s: findings from the HAPIEE Study. J Epidemiol Community Health 2014;68: 297-303.

2 Mackenbach JP, Stirbu I, Roskam AJR, et al. Socioeconomic inequalities in health in 22 European countries. New Engl J Med 2008:358:2468-81.

3 Maki N, Martikainen P, Eikemo T, et al. Educational differences in disability-free life expectancy: a comparative study of long-standing activity limitation in eight European countries. Soc Sci Med 2013:94:1-8.

4 Roelfs DJ, Shor E, Davidson KW, et al. Losing life and livelihood: a systematic review and meta-analysis of unemployment and all-cause mortality. Soc Sci Med 2011;72:840-54.

5 Galobardes B, Shaw M, Lawlor DA, et al. Indicators of socioeconomic position (part 1). J Epidemiol Community Health 2006;60:7-12.

6 Wahrendorf M, Dragano N, Siegrist J. Social Position, Work Stress, and Retirement Intentions: A Study with Older Employees from 11 European Countries. Eur Soc Rev 2013;29:792-802.

7 Börsch-Supan A, Brandt M, Schroder M. SHARELIFE-One century of life histories in Europe. Adv Life Course Res 2013;18:1-4.

8 Bambra C. Work, worklessness, and the political economy of health. Oxford: Oxford University Press, 2011.

9 Lahelma $E$, Lundberg 0 . Health inequalities in European welfare states. Eur J Public Health 2009:19:445-6.

10 Stuckler D, Basu S, Suhrcke M, et al. The public health effect of economic crises and alternative policy responses in Europe: an empirical analysis. Lancet 2009:374:315-23.

11 Siegrist J, Wahrendorf M. Quality of work, health and early retirement: European comparisons. In: Schroeder M, Hank K, Boersch-Supan A, eds. The Individual and the Welfare State-Life Histories in Europe. Berlin: Springer, 2010:169-177.

12 Dragano N, Siegrist J, Wahrendorf M. Welfare regimes, labour policies and unhealthy psychosocial working conditions: a comparative study with 9917 older employees from 12 European countries. J Epidemiol Community Health 2011;65:793-9. 